The Geneva Papers on Risk and Insurance, 22 (No. 83, April 1997) 151-176

\title{
Rethinking Society's Management of Catastrophic Risks*
}

\author{
by Howard Kunreuther **
}

\section{Introduction}

There is grave concern by the property and casualty insurance and reinsurance industry that they cannot continue along their current path of providing protection against certain risks or taking on additional risks without exposing themselves to the danger of insolvency or significant loss of surplus which will threaten the availability of future coverage. (Best Week, 1996). Consider the following three illustrative examples:

Natural hazards: Insured losses from Hurricane Andrew, which swept ashore along the Florida coastline in August 1992, topped $\$ 15$ billion. If the storm had taken a more northerly track so it would have hit downtown Miami Beach, total insured damage could have approached $\$ 50$ billion. (Insurance Research Council and Insurance Institute for Property Loss Reduction, 1995). Insured damage from the Northridge earthquake in southern California exceeded $\$ 12$ billion. Had a similar quake hit central Los Angeles the insured bill could have been over $\$ 50$ billion. A large quake in central Tokyo could have cost over $\$ 800$ billion (Giles 1994).

Technological risks: The explosion of Union Carbide's chemical tank at Bhopal in 1984 killed thousands of residents in the community and injured or created health problems for countless others. (Shrivastava 1987). The Clean Air Act Amendments of 1990 [Sect. 112(r)] requires that chemical facilities must develop risk management plans including emergency response measures and "worst case scenarios" with respect to substances that might cause major chemical accidents. To date, the insurance industry is reluctant to provide specific coverage for any of these substances. (Er et. al. 1996).

* This paper reflects many helpful discussions and comments from Neil Doherty, Bob Klein, Paul Kleindorfer, Jacqueline Meszaros, Mark Pauly, Tom Russell, and Sid Winter. An earlier version of the paper was presented at the European Society for Risk Analysis Annual Meeting in Guilford, England in June 1996. Special thanks to Christian Gollier, George Priest and Göran Skogh for their insightful points as discussants of the paper. Support from NSF Grant \# 5-24603 to the Wharton Risk Management and Decision Processes Center at the University of Pennsylvania is gratefully acknowledged.

** Wharton Risk Management and Decision Processes Center, University of Pennsylvania, Philadelphia, PA 19104. 
Environmental risks: Leaking underground storage tanks may create damage to municipal water supplies and adversely affect groundwater. In the United States alone there have been 185,000 confirmed releases with the total cost of remediation estimated to be between $\$ 30$ and $\$ 40$ billion. (Freeman and Kunreuther, in press). Providing insurance against leaking USTs does not appear to lead to catastrophic losses since each tank is independent of each other. On the other hand, the combination of precedent setting court judgments which may be retroactive in nature violates this independence assumption (Priest 1987). For example, suppose there were rulings next year which required a more stringent cleanup of land contaminated by USTs. Then insurers would find that their costs on all leaking USTs to be much higher than they had anticipated when setting a premium. Legislative initiatives, such as Superfund, have created new forms of liability which were never anticipated at the time that pollution insurance contracts were written and have caused pollution insurance to practically disappear (Doherty 1991).

These three examples raise questions as to what role insurance can play in reducing the probability of large losses from these natural and technological hazards as well as providing financial protection against disasters and accidents should they occur. The underlying concept which determines the importance of insurance in dealing with catastrophic risks is insurability. An event is insurable if the insurers can set a premium which both reflects the risk and enables them to make a profit. This implies that the resulting premium generates positive demand. If there is no market for coverage at the premium set by the insurer, then the risk will be deemed uninsurable.

If insurers are prohibited by regulators from setting a premium which reflects their risk, then insurers may decide to exit from this particular market because they feel that they will suffer net expected losses by offering coverage at the maximum rate they are allowed to charge. For example, if the insurer determined that there was a 1 in 25 chance of a home being destroyed by a hurricane, it would want to charge at least $\$ 40$ per $\$ 1000$ worth of coverage. Thus if its rates were restricted to $\$ 30$ per $\$ 1000$, then it will not want to offer insurance.

The purpose of this paper is to explore how insurance can be combined with other policy instruments, such as building codes and well-specified standards, to better manage these low probability high consequence (LP-HC) events than we are currently doing. The principal focus will be on the risks from natural disasters, but the concepts and principles discussed below are relevant for dealing with technological and environmental risks. Two recent developments provide the ingredients for rethinking the way society deals with catastrophic risks:

(1) There has been an emergence of new financial instruments, such as Act of God Bonds and catastrophe futures and options, for dealing with the potentially large losses from these risks. Although the volume of business to date in these instruments is relatively small, they offer promise for protection in the future, particularly if traditional insurance and reinsurance has only a limited role to play (Jaffee and Russell 1996).

(2) New advances in information technology (IT) and risk assessment offer an opportunity to estimate the chances and potential losses of future disasters and catastrophic events more accurately than in the past. On the IT side, the development of faster and more powerful computers enables one to examine extremely complex phenomena in ways that were impossible even five years ago. Scientific advances in risk assessment have reduced the 
uncertainty associated with predicting the chances and consequences of these LP-HC events. Insurers and reinsurers can more accurately estimate the premiums for providing protection against these risks and develop strategies for managing their portfolios so as to avoid sufficiently large losses which cause an unacceptable loss of surplus (Insurance Service Office 1996).

\section{Framework for analyzing catastrophic risks: the case of natural disasters}

The basic elements which characterize how society should deal with catastrophic risks are depicted in Figure 1. Initially one needs to delineate the nature of the problem and its importance. Given the interest here in insurance as a key policy instrument, the next phase is to determine whether the risk is insurable. The third element is an analysis of risk management tools which can supplement insurance to encourage the adoption of loss reduction measures and offer protection in the event of a major catastrophe.

Figure 1: Framework for analyzing catastrophic risks

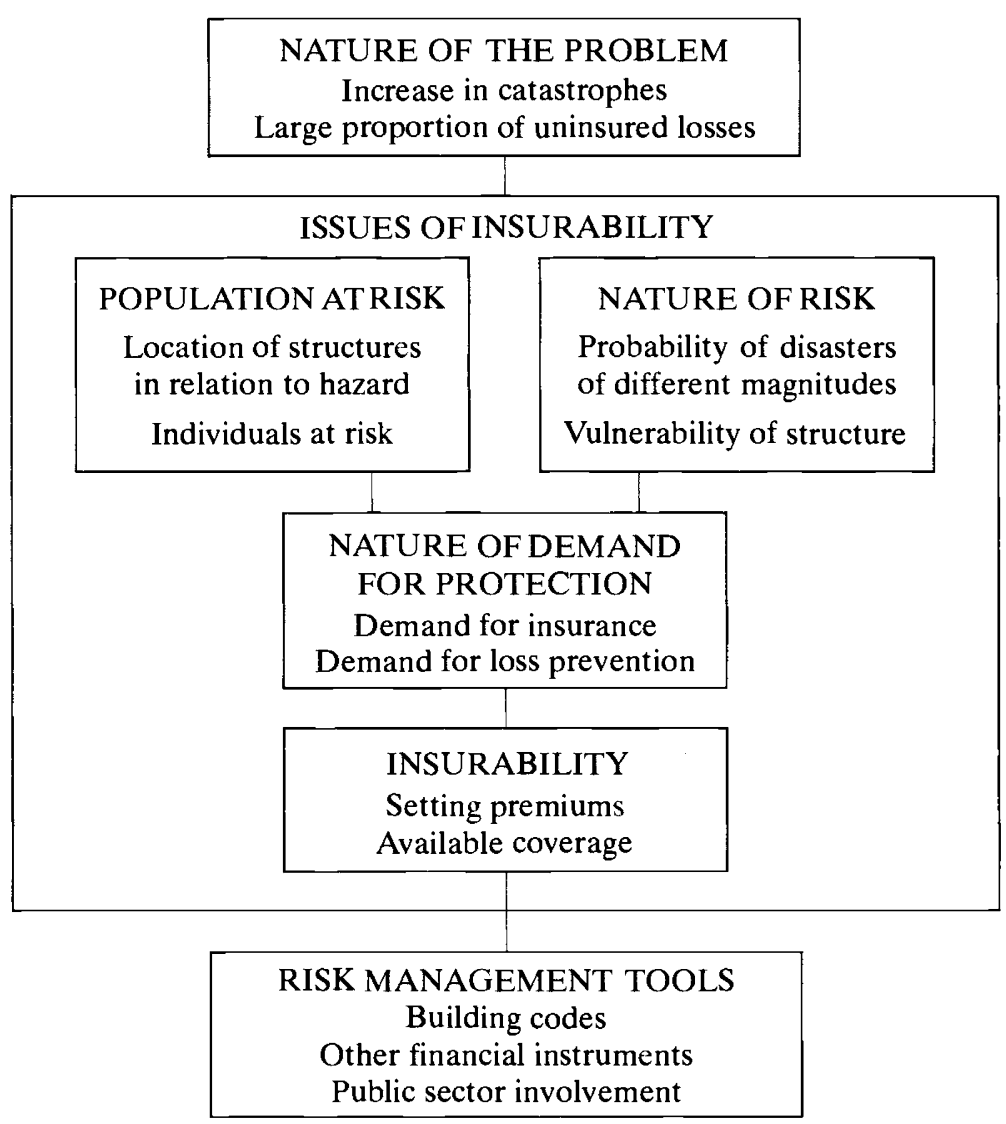




\section{Nature of the problem}

Natural disasters are now on the societal radar screen where they previously have received relatively little notice and attention, except after a catastrophic event. In the United States there has been increasing concern about the expenditures following recent disasters as illustrated by the following comment by two U.S. Congressmen:

Over the past five years the cost of natural disasters has been rising at an alarming rate. In that time, 11 catastrophes have cost the nation more than $\$ 1$ billion each. Hurricane Andrew and California's Northridge earthquake together cost more ( $\$ 24$ billion) than what the government spends annually on running the federal court system, aiding higher education and pollution control, combined (Emerson and Stevens 1995).

Although the insurance industry has suffered record losses from natural disasters in recent years, most of the damage from these events are covered from other sources of funds. In 1995 total estimated losses from natural disasters around the world accounted for $\$ 150$ billion which exceeded ten times the insured losses ( $\$ 14.6$ billion). More than half of this amount was accounted for by the Kobe earthquake where total damage was estimated at over $\$ 82$ billion, although insured losses were only $\$ 2.5$ billion (Sigma 1995 pp. 3-6).

\section{Evaluating insurability}

As shown in Figure 1 one first has to characterize the population at risk to determine whether a risk is insurable. For the natural hazards problem this would require one to construct a community or region consisting of homes, businesses and other properties which are subject to future disasters. More specifically, one would want to know the design of each structure, whether specific mitigation measures were in place or could be utilized and its precise location in relation to the hazard. (e.g. distance from an earthquake fault line or proximity to the coast in a hurricane-prone area).

To determine the demand for protection there is a need to specify the nature of the risk as accurately as possible. Normally this refers to providing estimates of the probability that disasters of specific magnitudes will occur and resulting losses to structures in harm's way. It is in this arena that great strides have taken place due to advances in IT. More specifically, new models of catastrophic losses have been developed which consist of two key components: the probability distribution of the hazard occurring (occurrence modeling) and the potential losses to different structures should a disaster occur (vulnerability modeling) (Walker 1996).

There has been considerable sophistication in modeling these processes for earthquakes and hurricanes in recent years so that it is now feasible to determine both the maximum probable losses of catastrophic events, their expected losses over a wide spectrum of events (i.e., the probability of disasters of different magnitudes multiplied by their impacts) and confidence intervals showing how much variation in these estimates is likely. ${ }^{1}$

The above two elements provide some indication of the nature of demand for protection. In addition to these demographic and physical features, one needs information on residents' and businesses' decision processes and their attitudes toward risk, the types of building

\footnotetext{
${ }^{1}$ More details on the modeling approaches for earthquakes and hurricanes can be found in Insurance Services Office 1996.
} 
codes and standards in place as well as the expectations residents in hazard-prone areas have of public subsidies following a disaster or accident. Section 3 provides more insight into why there is limited demand for both insurance and loss reduction measures.

A risk can be made more insurable by encouraging mitigation measures to reduce losses suffered by individual structures and hence the catastrophic potential from a disaster. This approach is widespread in other lines of insurance, such as fire and automobile coverage, but has had limited appeal to date when it comes to reducing losses from natural disasters. In fact, there has been a reluctance by the insurance industry to embrace the concepts of mitigation for natural hazards and provide premium reductions should certain measures be adopted (Walker 1996). ${ }^{2}$

Insurability is the critical element that determines the supply of coverage by the private sector. In theory, an insurer will examine the nature of the risk and determine how much coverage it will offer at different premiums so that its expected profit from insuring this risk is non-negative and its chance of becoming insolvent from an unusually large disaster is below some acceptable probability threshold. Insurability and its impact on the supply of insurance is analyzed in Section 4.

\section{Risk management tools}

The management of catastrophic risks requires a much broader set of policy tools than just insurance. Building codes that are enforced promise to reduce the loss potential from future large-scale disasters. New financial instruments which supplement reinsurance may alleviate the immediate financial problems faced by insurers in the aftermath of a catastrophic disaster or accident. A program for managing natural disasters which incorporates these and other policy tools is proposed in Section 5. These concepts have relevance to technological and environmental risks as well as natural disasters. Section 6 illustrates their application to these two areas by expanding on the examples presented in the introductory section. The concluding section suggests a program of research for examining new ways for society to cope more effectively with catastrophic risks.

\section{Factors influencing demand for protection}

Consider the following scenario to motivate the analysis regarding the demand for insurance and adoption of loss mitigation measures by residents in hazard-prone areas:

The Shaker family resides in an earthquake-prone area and wishes to protect itself against earthquake losses. There is great uncertainty regarding the annual probability (p) of a severe earthquake occurring in their area with estimates by seismologists ranging from $p_{\min }=1 / 40$ to $p_{\max }=1 / 10$. When pushed to give a most likely estimate, the scientists agreed to a value of $p=1 / 20$. Should an earthquake occur, the loss $(L)$ to the Shaker home is estimated at $L=\$ 50,000$. Minor earthquakes are not expected to do any damage to the Shaker property or its contents.

2 One of the reasons for this is that insurers have felt that, due to regulatory restrictions, current rates for these disasters are inadequate. If they promote a loss control measure and reduce premiums to reflect the decrease in risk, they would actually be encouraging residents in hazard-prone areas to purchase coverage. This would result in an increase in their future expected losses. 
The Shaker family has an interest in purchasing insurance protection against earthquake losses as well as possibly investing in mitigation measures. Their perception of the annual probability of an earthquake is $\pi=1 / 100$. The issue that the family confronts is whether they are willing to incur a certain upfront cost in the form of insurance premiums and/or expenditures for home improvements which yield uncertain future benefits.

\section{Demand for insurance}

Let us first consider the case where the property owner does not consider investing in loss mitigation measures and focuses on whether to buy insurance, and if so how much coverage to purchase. The empirical evidence suggests that few individuals voluntarily purchase insurance coverage against natural disasters unless they have personally experienced the event or know others who have suffered losses (Kunreuther et. al., 1978). Thus relatively little insurance was purchased by residents of Kobe prior to the January 1995 earthquake presumably because the city had never experienced a severe earthquake since its existence. ${ }^{3}$ Following the recent severe earthquakes in California during the past decade, voluntary demand for insurance increased because residents in affected areas are now concerned about future damage from these disasters (Palm, 1995).

Figure 2 depicts a model of choice for an individual's decision process. There is likely to be a threshold probability $p^{*}$ below which a person will not want to buy coverage because the attention costs of thinking about the event as well as the transaction costs of collecting information on insurance and making a decision on how much coverage to buy is too high. The higher these costs the larger will be $p^{*}$. Those who feel $\pi>p^{*}$ are likely to seek out friends and neighbors for information on where to buy coverage (Kunreuther et. al. 1978; Weinstein, 1987). If individuals use friends and neighbors to determine from which insurers to purchase coverage, then one would expect to find a clustering of policies with the companies who have successful regional agents. These insurers will face larger losses from a catastrophe than if a random search process had been utilized by consumers. ${ }^{4}$

The factors which determine the demand for insurance when individuals have the freedom to specify coverage limits are still not well understood, although recent controlled experimental studies provide insight into consumer decision processes. For example, there is evidence that framing manipulations impact on how consumers determine whether to purchase coverage and how much to pay. Some of these effects are the vividness of a projected event by the media, incorporating rebates so that the policyholder feels he has experienced a gain if he doesn't collect on his policy and the status quo serving as a reference point for deciding between options. Data from insurance markets indicate that these same effects occur when actual insurance decisions are made (Johnson et al. 1993). These findings suggest that one needs to rethink the theory of consumer choice regarding insurance.

\footnotetext{
${ }^{3}$ It may also have been the case that residents in Kobe were not able to purchase earthquake insurance without some time and effort in finding an insurer willing to offer coverage.

${ }^{4}$ It would be interesting to examine date from insurance companies to determine whether such a clustering effect is found in practice.
} 


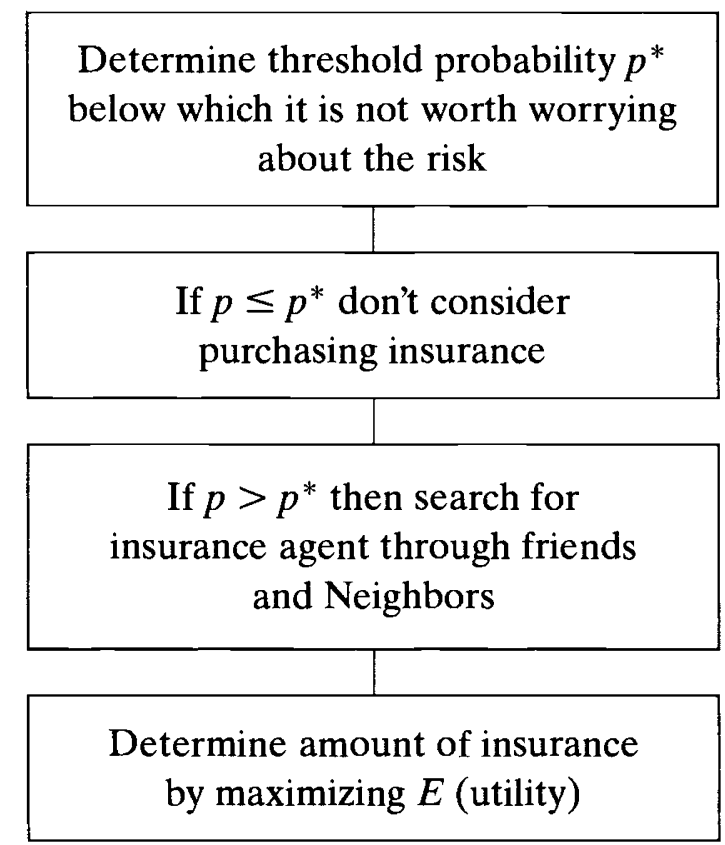

Source: adopted from Kunreuther et al. (1978).

In this paper I will assume that individuals who can voluntarily purchase insurance and perceive $\pi>p^{*}$, make benefit-cost tradeoffs that maximize their expected utility. ${ }^{5}$ The Appendix presents a simple model for examining the relationship between the premium charged per dollar of coverage $(z)$ and the perception of risk for determining how much insurance will be demanded. If $z \leq \pi$, then the individual will want to purchase full insurance. When $z>\pi$ then the individual will only consider purchasing partial coverage. Should $z / \pi$ be sufficiently high relative to the ratio of expected utilities in the disaster and nondisaster states, then no coverage will be demanded.

\section{Demand for loss prevention measures}

Now consider the case where the insured has an opportunity to engage in loss prevention activities at a cost of $\mathrm{x}$ dollars that reduce the amount of damage by $L(x)$ dollars. The relationship between loss prevention behavior and market insurance was first studied by Ehrlich and Becker (1972). They show that market insurance has two opposite effects on the incentive to adopt loss reduction measures (LRMs). On the one hand, insurance discourages the

5 The seminal study on the factors influencing the demand for insurance is by Arrow (1971). A comprehensive review of the literature appears in the paper by Dionne and Harrington (1992) as well as other papers in the volume edited by the two (Dionne and Harrington ed. 1992). 
adoption of loss prevention measures because it reduces the difference between the incomes in disaster and non-disaster states of the world. On the other hand, it encourages individuals to adopt mitigation measures if the premiums reflect the decrease in expected loss. ${ }^{6}$

There is considerable empirical evidence suggesting that few property owners have been willing to invest funds in cost-effective mitigation measures in hazard-prone areas. In a 1989 survey of 3,500 homeowners in four California counties subject to earthquake damage, only between 5 and 9 percent of the respondents in each of these counties reported adopting any LRMs (Palm et.al. 1990). A follow-up survey of residents affected by the October 1989 Loma Prieta earthquake by Palm and her colleagues and the Northridge earthquake of 1994 revealed that only 10 percent of homeowners invested in any type of structural loss-reduction measure whether or not they were affected by recent earthquakes in the State (Palm 1995).

Suppose that the Shaker family is interested in investing in a protective measure without having purchased any insurance and having to fend for themselves financially after suffering a disaster loss. The family has wealth $W$ and is assumed to be risk neutral so that $U(W)=W$ and has an annual discount rate $(\mathbf{r})$. The Appendix shows how to determine the optimal amount of protection $\left(x^{*}\right)$ if the structure is expected to last for $T$ years and the reduction in losses from mitigation is characterized by $L(x)=L-100 \log (x){ }^{7}$

Table 1 details the value of $x^{*}$ for three different time horizons $(T=1,5$ and 10), $r=0.10$ and two estimates of the annual probability of a disaster: the experts' best estimate $(p=1 / 20)$ and the Shaker's perception $(\pi=1 / 100)$. The analysis assumes that each additional dollar invested in mitigation yields some extra benefit in potential loss reduction. In reality, mitigation measures require discrete chunks of money, such as investments of $\$ 1500$ to bolt a foundation to the structure to make it earthquake proof. Note that if the Shakers' consider only a one year time horizon then they will invest very little in mitigation (i.e. $x^{*}=0.9$ ). At the other extreme, with $T=10$ and utilizing the expert's estimate $(p=1 / 20)$ then $x^{*}$ increases to 18.4 .

Table 1:

Optimal investment in mitigation $\left(x^{*}\right)$ as a function of probability disaster and time horizon*

$\begin{array}{lccc}\begin{array}{l}\text { Probability } \\ \text { of disaster }\end{array} & \text { 1 year } & \text { Time horizon }(T) & 5 \text { years } \\ p=1 / 20 & 4.3 & 14.7 & 10 \text { years } \\ \pi=1 / 100 & 0.9 & 3.6 & 18.4\end{array}$

* Note: $x *$ is determined using $U(W)=W, L(x)=L-100 \log (x)$ and $r=0.10$.

${ }^{6}$ Building on the Ehrlich and Becker result, Dionne and Eeckhoudt (1985) investigate the impact of risk aversion and Hiebert (1989) on loss uncertainty on the incentive to employ mitigation measures. Kunreuther and Kleffner (1992) compare the demand for loss prevention measures when a consumer is fully insured or has no coverage.

${ }^{7}$ Since $U(\mathrm{~W})=W$, the value of $x^{*}$ is independent of the values of $W$ and $L$. If the property owner were risk averse both $W$ and $L$ would play a role in determining $x^{*}$. 
At a more general level, if the investment in loss reduction measures is reflected in an increase in property values that fully captures the expected decrease in expected damage from future disasters, then the market will lead individuals to make the optimal decision without having to explicitly do the calculations indicated in Table 1. If, on other hand, both residents in hazard-prone areas and potential buyers of their property underestimate the risk of a disaster, then the investments will not be adequately reflected in property values. The empirical evidence suggests that property owners underestimate the risk given their lack of interest in adopting these measures.

Another factor which may lead to an under-investment in cost-effective mitigation measures is the short-time horizons or extremely high discount rates that individuals (both potential buyers and current owners) utilize in evaluating the expected benefits of protective measures. ${ }^{8}$ For this reason, certain investments will not be viewed as cost-effective by those residing in hazard-prone areas, even though they are deemed as financially attractive by the insurer who takes into account the expected length of the life of the structure in evaluating specific mitigation measures.

A third factor, which may limit the ability of the homeowner or businessman to invest in a protective measure, is a budget constraint. If the cost to reinforce ones structure is $\$ 1500$ and the savings on ones annual insurance premium is only $\$ 500$, then the investment may be viewed as unaffordable even if the expected benefits over a 5 year time horizon would more than justify the cost. ${ }^{9}$

\section{Summary}

There is a general lack of interest by individuals in voluntarily purchasing insurance because they underestimate the probability of the event occurring, use sequential models of choice and may misestimate the losses. There is an increase in the demand for coverage following disasters because the event is salient in many people's mind, so that its perceived probability exceeds the threshold level of concern. Those who do consider purchasing coverage often rely on friends and neighbors for information on which to base their decision.

With respect to the adoption of mitigation measures, relatively few residents of hazardprone areas invest in cost-effective LRMs. Their reluctance to consider loss prevention measures appears to be due to short planning horizons, underestimates of probability of the disaster and/or budget constraints. Insurers who have more accurate information on the risk and the relevant time horizon than consumers should want to encourage the adoption of these measures.

${ }^{8}$ A set of experiments by Lowenstein (1987) on willingness to pay for items where the benefits were delayed revealed that the implied discount rates are considerably higher than market rates, particularly in situations where the expected savings over time are small relative to the upfront expenditure.

${ }^{9}$ With a discount rate of $r=0.10$, the expected benefits from investing in the measure would be over $\$ 1,800$ with $p=1 / 20$. 


\section{The supply of insurance}

A literature has developed in recent years which suggests that insurers and other firms are risk averse and hence they must be concerned with non-diversifiable risks such as the possibility of catastrophic losses from disasters (Mayers and Smith, 1982).10

Suppose employees of an insurance firm are risk averse and there are transaction costs associated with bankruptcy. Then the firm will want to charge higher premiums than implied by the expected losses due to the possibility of catastrophes, even when their shareholders can costlessly eliminate this risk through their own portfolio diversification. In other words, higher premiums will be charged on the basis of portfolio risk not individual policy risk. These arguments also may explain the demand for reinsurance by property/liability companies (Mayers and Smith 1990). ${ }^{11}$

Insurers are also likely to be ambiguity averse in that they are concerned with the uncertainty regarding the probability of a loss occurring. Actuaries and underwriters both utilize heuristics which reflect these concerns. Actuaries normally determine a premium based on expected value by assuming that the probability and loss are known. They then increase this value to reflect the amount of perceived ambiguity in the probability and/or uncertainty in the loss. One commonly used formula for determining a premium is $z=(1+\lambda) \mu$ where $\mu=$ expected loss (i.e. $p \times L$ ) and $\lambda>0$ is a factor reflecting ambiguity and uncertainty independent of any adjustment to cover administrative costs (Lemaire 1986).

Underwriters make their decision regarding whether a risk is insurable by utilizing the actuary's recommended premium $z$ as a reference point and then focus on the impact of a major disaster on the probability of insolvency. In other words, underwriters are first concerned with the firm's safety and then with profit maximization. ${ }^{12}$ Stone (1973) formalized these concepts by suggesting that an underwriter who wants to determine the conditions for a specific risk to be insurable will first focus on keeping the probability of insolvency below some threshold level $\left(q^{*}\right)$. More specifically, suppose that the insurer expects to sell $m$ policies, each of which can create a loss $L$. Then the underwriter will recommend a premium $z^{*}$ so that the probability of insolvency is no greater than $q^{*}$. Risks with more uncertain losses or greater ambiguity will cause underwriters to want to charge higher premiums for a given portfolio of risks. The situation will be most pronounced for highly correlated losses, such as earthquake policies sold in one region of California. A more formal model for the underwriter's decision process is specified in the Appendix..$^{13}$

${ }^{10}$ See Froot et. al. (1994) for a discussion of the increasing role that risk management tools are playing in how corporations are doing business today.

11 Doherty and Tinic (1982) have argued that demand for reinsurance is generated by insurers anticipating policyholders' aversion to bankruptcy.

12 A safety-first model of firm behavior was first proposed by Roy (1952). Such a model can be contrasted with a value maximization approach to firm behavior. A safety-first model explicitly concerns itself with insolvency when making a decision regarding maximum amount of coverage and premiums to charge. A value maximization model recognizes that firms are risk averse so that premiums will have to be higher to reflect the chances of a catastrophic loss. It does not explicitly focus on keeping the probability of insolvency below some prespecified level.

13 A more detailed discussion of the decision processes utilized by actuaries and underwriters in insuring ambiguous risks can be found in Kunreuther (1989). 
A safety-first model of underwriter behavior is consistent with the Mayers and Smith (1990) rationale as to why insurance firms want to purchase reinsurance. In fact, a rule that focuses on keeping the chances of insolvency below $q^{*}$ explicitly recognizes the role that risk plays in the decision process. By explicitly characterizing the underwriter's behavior in this way, one can then examine the role that reinsurance and other financial instruments can play in alleviating these concerns. We will address this point more explicitly in the next section.

The empirical evidence based on surveys of underwriters supports the hypothesis that insurers will set higher premiums when faced with ambiguous probabilities and uncertain losses rather than a well-specified risk. A questionnaire was mailed to underwriters of primary insurance companies and reinsurance firms asking them to specify the prices which they would charge to insure a factory against property damage from a severe earthquake under the following four different cases: Case 1: well-specified probabilities $(p)$ and known losses $(L)$; Case 2: ambiguous probabilities $(A p)$ and known losses; Case 3: well-specified probabilities and uncertain losses $(U L)$ and Case $4:$ ambiguous probabilities and uncertainty losses. ${ }^{14}$

For the non-ambiguous case, the probability of the earthquake $(p)$ was set at either 0.01 or 0.005 and the loss should the event occur $(L)$ was specified at either $\$ 1$ million or $\$ 10$ million, yielding four different scenarios..$^{15}$ If one standardizes the premium set by the underwriter at 1 for the non-ambiguous case, then one can examine how ambiguity affects pricing decisions. Table 2 depicts the ratio of the other three cases relative to the nonambiguous case $(p, L)$ for the four different scenarios which were distributed randomly to underwriters in primary insurance companies. For the highly ambiguous case $(A p, U L)$, the premiums were between 1.43 to 1.77 times higher than if underwriters priced a non ambiguous risk. The ratios for the other two cases were always above 1 but less than the $(A p, U L)$ case (Kunreuther et al. 1995).

An analysis of these and other data on underwriters' responses to questions such as these suggests that a safety-first model characterizes their behavior (Berger and Kunreuther 1994). Interview data with several insurance companies in the United States concerned with the impact of recent natural disaster losses on their future activity provides additional evidence that firms follow a safety-first model. Prior to Hurricane Andrew (1992) and the Northridge earthquake (1994), these insurers were not worried about the potential impact of losses to their portfolio from severe hurricanes and earthquakes and hence did not attempt to restrict coverage and/or make the case for higher premiums because of the likelihood that they would become insolvent. Hence they did not focus on the survival constraint in their insurance decisions.

${ }^{14}$ An ambiguous probability refers to the case where "there is wide disagreement about the estimate of $p$ and a high degree of uncertainty among the experts". A well-specified loss $(L)$ means that all experts agree that if a specific event occurs the loss will equal $L$. An uncertain loss refers to the situation where the experts' best estimate of a loss is $L$ with estimates ranging from $L_{\min }$ to $L_{\max }$. (Kunreuther et al., 1995).

15 These well-specified scenarios were $p=0.005 L=\$ 1$ million or $L=\$ 10$ million and $p=0.01$ $L=\$ 1$ million or $\$ 10$ million. 
Table 2:

Ratios of underwriters' premiums for ambiguous and/or uncertain earthquake risks relative to well-specified risks

\begin{tabular}{|l|l|l|l|l|l|}
\hline \multirow{2}{*}{ SCENARIO } & \multicolumn{5}{|c|}{ CASES } \\
\cline { 2 - 6 } & \multicolumn{1}{|c|}{1} & 2 & 3 & 4 & \\
\cline { 2 - 6 } & $\mathrm{p}, \mathrm{L}$ & $\mathrm{Ap}, \mathrm{L}$ & $\mathrm{p}, \mathrm{UL}$ & $\mathrm{Ap}, \mathrm{UL}$ & $\mathrm{N}$ \\
\hline $\begin{array}{l}p=0.005 \\
L=\$ 1 \text { million }\end{array}$ & 1 & 1.28 & 1.19 & 1.77 & 17 \\
\hline $\begin{array}{l}p=0.005 \\
L=\$ 10 \text { million }\end{array}$ & 1 & 1.31 & 1.29 & 1.59 & 8 \\
\hline $\begin{array}{l}p=0.01 \\
L=\$ 1 \text { million }\end{array}$ & 1 & 1.19 & 1.21 & 1.50 & 23 \\
\hline $\begin{array}{l}p=0.01 \\
L=\$ 10 \text { million }\end{array}$ & 1 & 1.38 & 1.15 & 1.43 & 6 \\
\hline
\end{tabular}

$\mathrm{N}=$ Number of respondents

${ }^{*}$ Ratios are based on mean premiums across number of respondents for each scenario.

Source: Adapted from Table 3 in Kunreuther et. al. (1995).

In the aftermath of these two disasters, company executives have modified their view and are concerned that they cannot survive a future catastrophe given their current portfolio and the amount of reinsurance coverage that they can obtain at a reasonable price..$^{16} \mathrm{In}$ other words they feel that the chances of insolvency based on their current portfolio exceeds their threshold level of concern $\left(q^{*}\right)$. Hence they either want to reduce the number of policies they write in catastrophic-prone areas, raise their per unit premiums $z$, and/or obtain more reinsurance coverage. In the United States insurers have had problems undertaking these actions for the following reasons:

Regulatory constraint: In Florida, for example, the percentage of homeowners policies that an insurer can cancel or non-renew in any one year is required to be less than 5 percent statewide and 10 percent in any one county until November 1996. Insurers who offer coverage in Florida are also forced to share in the future losses of those individuals who buy

16 These observations are based on a series of personal interviews with insurers and reinsurers conducted by Jacqueline Meszaros as part of a National Science Foundation study to the University of Pennsylvania, on "The Role of Insurance and Regulation in Dealing with Catastrophic Risk". The results will appear in a paper to completed in 1997. 
coverage from a Residential Joint Underwriting Association (JUA). These JUAs were set up to provide coverage to those homeowners who could not purchase or renew their policy from a private insurer. Hence they generally represent a higher risk but may be charged premiums below the actuarially fair rate (Insurance Information Institute 1995). Today this residual market mechanism is the state's third largest property insurer having underwritten almost 900,000 policies and exposing itself to $\$ 100$ billion in potential losses (Scism, 1996). ${ }^{17}$

Limited reinsurance: Insurers have had a difficult time finding enough reinsurance to protect themselves against catastrophic losses. Today an individual company can purchase at most $\$ 300-\$ 400$ million in reinsurance to cover catastrophes at premiums that they are willing to pay. This may be sufficient to cover smaller firms but will be insufficient to cover companies such as State Farm which stands to lose about $\$ 10$ billion in a $\$ 50$ billion catastrophe. (Mooney 1995). On a broader level there is great concern in the industry with the potential impact of a future catastrophic earthquake or hurricane where insured damage could be over $\$ 100$ billion. The insurance and reinsurance industry feels it will not have enough capacity to cover future losses from such an earthquake. Although the total annual capacity worldwide is hard to estimate, it is unlikely to be more than $\$ 50$ billion (Valery 1995).

Limited enforcement of building codes: The other problem that insurers face in setting premiums for structures in hazard-prone areas is not knowing whether or not the house is designed according to code and/or whether specific mitigation measures are put in place. This is a type of ex ante moral hazard to the extent that there is a conscious effort by local and state governments not to enforce codes through inspections of individual structures. ${ }^{18}$ Insurance experts have indicated that a substantial amount of the insured losses from Hurricane Andrew could have been prevented through better building code compliance and enforcement (Insurance Research Council and Insurance Institute for Property Loss Reduction, 1995).

If the insurer does not know the nature of the accident and hence cannot determine whether the damage claim is exaggerated then it faces ex post moral hazard. ${ }^{19}$ An example of such behavior in the context of natural hazards would be moving old furniture that the family wants to have replaced from the first floor to the basement when hearing of flood warnings. Another example would be claiming damage from a disaster (e.g. cracks in the ceiling) that were present prior to the event.

\section{Summary of insurability issues}

The insurance and reinsurance industry today is concerned with the magnitude of losses from catastrophic events because most firms perceive that another major disaster could cause them to become insolvent. Hence underwriters are focusing on their survival constraint when determining what type of coverage can be profitably offered and how many

17 State regulators have come under increasing pressure to maintain oversight of insurers' solvency and market practices in recent years. For a more detailed discussion of the changing role of the state regulator given these pressures and recent reforms that have been undertaken, see Klein (1995).

${ }^{18}$ For a more detailed discussion of ex ante moral hazard see Pauly (1974), Marshall (1976), Shavell (1979) and Dionne and Harrington (1992).

${ }^{19}$ See Spence and Zeckhauser (1971) and Dionne and Harrington (1992) for a more detailed discussion of ex post moral hazard in the context of insurance problems. 
policies should be sold. Many insurers in United States would like to reduce the amount of coverage and charge higher premiums. Since they are restricted from doing this by regulatory authorities, they want to withdraw from hazard-prone areas (e.g. hurricane-prone in Florida and earthquake-prone in California). In other words, given the current climate these insurers consider such risks to be unsinsurable.

These concerns by insurers raises the question as to the future role of the private market in providing financial protection against losses from catastrophic events. Property owners who are interested in buying insurance or who are required to purchase coverage as a condition for a mortgage are now having difficulty obtaining policies at affordable rates. Insurers are now taking steps to withdraw from certain markets because they feel the premiums they are forced to charge are too low and the number of policies they are required to provide in hazard-prone areas is too great. They believe that this combination places them in a precarious financial position should another catastrophic disaster occur in these areas.

\section{A proposed program for dealing with catastrophic risks}

We need a fresh approach for dealing with the catastrophic risks from natural and technological hazards. Fortunately, it is possible for us to think more broadly about managing these risks in the future due to the advances in information technology for analyzing and managing data, and the availability of new financial instruments for supplementing traditional reinsurance. These developments suggest a strategy which consists of the following elements to be discussed in more detail below: (1) Improving Risk Estimates, (2) Role of Audits and Inspections and (3) Broading Protection Against Catastrophic Losses.

Two general observations should be made before outlining the details of such a program:

* Insurance is likely to play a key role in this new world.

* One needs to involve other stakeholders and policy instruments to complement the use of insurance in reducing losses while providing protection once a disaster occurs.

\section{Improving the estimates of the risk}

There are two principal reasons why insurers will benefit from improved estimates of the risk associated with catastrophes. By obtaining better data on the probabilities and consequences of these events, insurers will be able to more accurately set their premiums and tailor their portfolio to reduce the chances of insolvency. Providing more accurate information on the risk also reduces the asymmetry of information between insurers and other providers of capital such as reinsurers and the financial investment community. Investors are more likely to supply capital if they are more confident in the estimates of the risks provided to them by the insurers.

In setting rates for catastrophic risks insurers have traditionally looked backwards by relying on historical data to estimate future risks. ${ }^{20}$ Such procedures are likely to work well if there is a large data base of past experience which forms the basis for extrapolation into the future. Low probability-high consequence events generally have a relatively small

20 I am grateful to Terry Van Gilder of Risk Management Solutions, formerly chief underwriter at Chubb, for characterizing the decision process of insurers in this way. 
historical data base. In fact, many technological and environmental risks are associated with new processes so that past performance data are lacking. One thus has to rely on scientific modeling and epidemiological data to estimate these risks.

Fortunately there is considerable scientific work undertaken in the areas of natural, technological and environmental hazards to provide estimates of the probabilities and consequences of events of different magnitudes. ${ }^{21}$ In many cases there is some diversity and contention among the experts as to the potential risks from hazards or technologies. For example, scientific knowledge on the probability of earthquakes of different magnitudes has been growing rapidly since the 1960 s and there is still no consensus as to what figures should be the basis for seismic probability maps. (Mittler, Taylor and Petak 1995). On the other hand, it should be possible to construct statistical confidence intervals for characterizing these risks, even though they may be quite high.

The advances in information technology have encouraged catastrophe modeling because it is possible to simulate a wide variety of different scenarios which reflect the uncertainties in these estimates of risk. For example, it is feasible to evaluate the impact of different exposure levels by insurers on both expected losses as well as maximum possible losses by simulating a wide range of different estimates of seismic events by using the data generated by scientific experts. Similar studies can be undertaken to evaluate the benefits and costs of different building codes and loss prevention techniques (Insurance Services Office 1996).

Today there are a growing number of catastrophe models that have been utilized to generate data on the likelihood and expected damage to different communities or regions from disasters of different magnitudes or intensity. Each model uses different assumptions, different methodologies, different data and different parameters in generating their results. Hence the need for a better understanding as to why these models differ in attempts to reconcile these differences in a more scientific manner than has been done up until now.

\section{Role of audits and inspections}

In order to avoid problems of moral hazard and adverse selection while at the same time rewarding those who undertake loss reduction measures (LRMs), it is often necessary to undertake audits and inspections. With respect to properties at risk, one way to encourage the adoption of cost effective LRMs is to have them incorporated in building codes and provide a seal of approval to each structure that meets or exceeds these standards..$^{22}$

To institutionalize such a procedure financial institutions could require an inspection and certification of the facility against natural hazards as a condition for obtaining a mortgage. ${ }^{23}$ This inspection, which would be a form of buyer protection, is similar in concept to termite

21 For example, a discussion of new advances in seismology and earthquake engineering can be found in Federal Emergency Management Agency (1994) and Office of Technology Assessment (1995).

22 Kunreuther and Kleffner (1992) provide a rationale for strengthening building codes by analyzing the factors which lead individuals to avoid investing in mitigation measures even if they have accurate information on the risk.

23 Such procedures are not routinely undertaken by banks today even though it is in their interest to know as much about the risk as possible to protect their mortgage. 
and radon inspections normally required when property is financed. The success of such a program requires the support of the building industry and a cadre of well-qualified inspectors to provide accurate information as to whether existing codes and standards are being met.

To reduce their losses from disasters, insurers may want to limit coverage only to those structures that are given a seal of approval. To encourage the adoption of additional costeffective LRMs, insurers can provide financial incentives in the form of lower premiums, lower deductibles or increased limits of coverage. ${ }^{24}$ If budget constraints prevent property owners from investing in these mitigation measures, then the bank can provide funds through a home improvement loan with a payback period identical to the life of the mortgage.

Consider the following example where the cost $(x)$ of an earthquake mitigation measure is $\$ 1500$. If the annual probability of an earthquake is $p=1 / 100$ and the reduction in loss from investing $x=\$ 1500$ is $L-L(x)=\$ 27,500$, then the expected annual benefit is $\$ 275$. A 20 year loan for $\$ 1500$ at an annual interest rate of 10 percent would result in payment of $\$ 145$ per year. If the annual premium reduction from insurance reflected the expected benefits of the mitigation measure (i.e. \$275) then the homeowner will have lower total payments by investing in mitigation than not undertaking the measure.

Many poorly constructed homes are owned by low-income families who cannot afford the costs of mitigation measures on their existing structure nor the costs of reconstruction should their house suffer damage from a natural disaster. Equity considerations argue for providing this group with low interest loans and grants for the purpose of adopting costeffective LRMs or for them to relocate their home to a safer area. Since low income victims are likely to receive federal assistance after a disaster, subsidizing these mitigation measures can also be justified on efficiency grounds.

\section{Broadening protection against catastrophic losses}

New sources of capital from the private and public sectors have the possibility of providing insurers with funds against losses from catastrophic events so as to alleviate their concerns that they may be insolvent from the next major disaster. This section briefly examines some options currently on the table.

New financial instruments: Over the past few years a number of new financial instruments in the form of derivatives ${ }^{25}$ have been developed for dealing with catastrophic losses, although to date they have had limited market penetration. These instruments infuse the insurer with additional capital should there be a catastrophic loss. In other words, catastrophe exposures would be treated as a new asset class. Each of the instruments could be priced using models which incorporated the risk and magnitudes of the disaster and the amount of coverage provided. Furthermore, insurers could supplement traditional reinsurance with these guaranteed sources of funds in order to relieve the safety-first constraint which may be restricting their ability to offer coverage in high risk areas.

${ }^{24}$ Zeckhauser (1995) has shown that if an insured individual is risk averse, he will be more likely to undertake loss prevention measures if his insurance policy is capped at some maximum value rather than by offering him a higher deductible. He shows that such a policy avoids the problem of distribution distortion.

25 A derivative is a bilateral contract in which one party has an obligation to another if certain conditions occur (e.g. a disaster where insured losses exeeds some prespecified dollar figure). For more details on the nature of derivatives see Culp (1996) pp. 4-10. 
J.P. Morgan and Nationwide Insurance successfully negotiated such a transaction whereby Nationwide borrowed $\$ 400$ million from J.P. Morgan which is placed in a trust fund composed of U.S. treasury securities. Nationwide pays a higher than normal interest rate on these funds in return for having the ability to issue up to $\$ 400$ million in surplus notes to help pay for the losses should a catastrophe occur (Mooney 1995). A similar financial arrangement, but one with more extreme consequences to investors, is Act of God bonds. Here investors provide capital to be used by the insurer if a catastrophe occurs, obtaining a large return on their investments (e.g. 15 percent) to reflect their risk. Both these financial products address the solvency constraint associated with the safety-first model, as shown in the Appendix.

Litzenberger et. al. (1996) have simulated 10,000 scenarios which estimate the average rate of return of 10 year CAT bonds to be somewhere between $7.47 \%$ and $7.88 \%$. This compares with an average return of $5.61 \%$ for 10 year high yield bonds. Froot et al. (1995) computed the returns an investor would have earned by providing capital to fund "excess of loss" reinsurance contracts during the period of 1970 to 1994 . They found that an investor would have earned returns of 224 basis points above the Treasury bill rate during this entire period. In the best and worst years over this time horizon the excess return would have been $7.5 \%$ and $-22.1 \%$ respectively.

Other financial instruments are catastrophic insurance futures contracts and call spreads introduced by the Chicago Board of Trade (CBOT) in 1992. They enable an insurer to hedge against their underwriting risk by attracting capital from insurance and non-insurance segments of the economy. ${ }^{26}$ Here the benefits are based on the magnitude of catastrophic losses from the disaster to the entire insurance industry (i.e., basis risk) rather than to a specific firm. In other words, the underwriter has less control over the revenue flowing into the firm after a disaster because it is based on total coverage written by all insurers. For this reason this instrument is likely to be less attractive to any insurer the less its risk of a specific event is correlated to the entire portfolio of insurance. ${ }^{27}$

Another new marketplace is the Catastrophic Risk Exchange (CATEX) where insurers, brokers and self-insured can swap "standardized catastrophe units" by region and peril according to values assigned by an impartial party such as the Nasdaq stock market system. From these companies' perspective it is a way of diversifying risk across hazards by giving up portions of their coverage in one part of the country while assuming additional risk in another region. An example of such a CATswap would be a trade of $\$ 3$ million of California earthquake insurance for an equal amount of Florida windstorm exposure (Insurance Services Office 1996).

Insurance pools and public sector programs: Because of the magnitude of real and potential disaster losses, and the consequent effects on the insurance industry and on financial markets, legislatures have begun to provide some security and stability for financing catastrophic losses experienced by insurers. State-mandated insurance pools for windstorm risks have existed for some time in many coastal areas but they are limited in geographic

${ }^{26}$ See Cummins and Geman (1995) and Harrington, Mann and Niehaus (1995) for a more detailed discussion on these hedging mechanisms and the challenges in pricing them.

27 To date the CBOT has not had much success in selling these futures contracts. Recently they introduced a new option based on the value of an index compiled by the Property Claim Services (PCS). For more details on these options see Culp (1996) pp. 31-42. 
coverage and in their ability to provide financial assistance following a severe disaster. Furthermore they are regulated by elected insurance commissioners so that the rate setting process and availability of coverage to those in disaster areas are affected by political considerations.

In September, 1996 the California state legislature approved the formation of the California Earthquake Authority (CEA) which provides coverage to homeowners with a 15 percent deductible. The CEA is an innovative arrangement which reflects a combination of both private and public funding to cover the insured losses from a catastrophic disaster. Insurers' liability is limited to $\$ 6$ billion ( $\$ 1$ billion in start-up assessments, $\$ 3$ billion for the first layer of coverage to pay claims after an earthquake and another $\$ 2$ billion if the insured damage exceeds $\$ 8.5$ billion). The other layers are funded by either reinsurance ( $\$ 2$ billion), policyholder assessment ( $\$ 1$ billion) to cover a loan from the bond market and the capital markets ( $\$ 2$ billion) (Russell and Jaffee, 1996; Roth in press). These state efforts are barely adequate for a limited disaster, let alone the mega-catastrophe that is well within the range of probability.

A successful example of the use of an insurance pool is the coverage of catastrophic losses from nuclear power plant accidents in the United States. A group of private insurers provides coverage for losses up to $\$ 7.2$ billion. The German Pharmaceutical pool, consisting of private insurers and reinsurers from all over Europe, operates in a similar fashion by providing protection against large risks by private drug manufacturers associated with new drugs (Kunreuther 1989).

The National Economic Council (NEC) has developed a proposal recommending that the federal government offer catastrophe reinsurance contracts that would be auctioned annually. The proposal would establish a program in which the Treasury would auction a limited number of excess-of-loss contracts covering industry losses between $\$ 25$ billion and $\$ 50$ billion from a single natural disaster. Insurers, reinsurers and state and national catastrophe pools would be eligible purchasers. Contracts would be sold to the highest bidder above a base reserve price which is risk-based. Half of the proceeds above the reserve price would go into a mitigation fund, with the remainder retained to cover payouts. The task force envisioned the reinsurance program starting to phase out after five years in expectation that a private market would emerge for this level of coverage (Lewis and Murdoch 1996).

Another option is for the Federal government to provide reinsurance protection against catastrophic losses. Private insurers would build up the fund by being assessed premium charges in the same manner that a private reinsurance company would levy a fee for excess loss coverage or other protection. The advantage of this approach is that resources at the Federal government's disposal enable them to cover catastrophic losses without charging insurers the higher risk premium that private investors would require. If one views the private sector as the first line of attack on the problem, then one would only want to resort to federal reinsurance as an avenue of last resort.

\section{Extensions to other hazards}

Although natural hazards have been used as an illustrative example, similar principles are relevant to firms which face technological and environmental risks. In this section I will examine some of the challenges that insurers face in these areas and the need to involve other interested parties using the two illustrative examples presented in the Introductory section. 


\section{Technological risks}

Suppose that a chemical plant would like to purchase insurance protection against the losses from an explosion or major accident which could produce physical damage to the facility as well as cause losses, injuries and deaths to the surrounding area. The same type of questions discussed in the context of natural hazards would arise for these technological risks.

The degree of uncertainty and ambiguity of the risk depends on the data available on previous accidents in chemical plants, the type of scientific modeling of causes of accidents of different magnitudes as well as the types of risk management plans that the company has implemented to reduce the chances and magnitudes of accidents. New advances in information technology should enable one to do a more complete analysis of alternative scenarios regarding these accidents in order to determine the range of expected losses as well as the nature of worst case scenarios.

Insurers are much more concerned with the liability that they face with technological risks than for natural disasters. In particular, they face the problem of public moral hazard, ${ }^{28}$ which refers to the public blaming "unexplained" adverse health effects following a chemical release on the accident even though the illness (real or imagined) was caused by other factors. If the insurer believes that they will be forced to cover these unfounded claims following an accident, the premium will have to reflect this risk.

As with natural hazards there are potential benefits to inspections of the chemical facility to both estimate the risk as well as determine what loss prevention measures have been undertaken. These audits can be undertaken by the insurer itself or a third party such as a certified inspector. The inspection process will enable important risk data to be collected, synthetized and analyzed so that one has better estimates of the risk. There are two factors which inhibit the use of these inspections:

(1) the difficulty in determining what constitutes a safe facility

(2) concern with liability by the inspector if there is an accident which occurs after the facility is certified to be safe.

For both these reasons it may be necessary to specify standards and requirements which guide the process. A good example of a case where third party inspections have worked extremely well is in the regulation of steam boilers where 43 states in the U.S. require boiler inspections on a regular basis. Statutory codes have been specified by an industry trade association and serve as the basis for judging the performance of the boiler (Er 1996).

If the insurer faces a potentially large loss from a catastrophic accident in relation to its surplus then it is in the same boat as with the natural hazards risk. It will require some form of protection through a combination of reinsurance/new financial instruments or government assistance. To the extent that the insurer provides coverage against accidents facing a large number of industrial facilities, then it will be less concerned with the impact of a single accident on its surplus. However, the insurer may still want to arrange to have an infusion of capital in the spirit of the Nationwide/J.P. Morgan agreement, just in case it experienced an unusual number of accidents during a short period of time.

28 The term "public moral hazard" was suggested by Paul Kleindorfer. It is discussed in more detail in Er et al. (1996). 


\section{Environmental risks}

For environmental risks, such as leakage from underground storage tanks (USTs) or other forms of groundwater contamination, there is the basic question as to what the insurer would be expected to cover in terms of claim payments. The linkage between the magnitude of damage and the risk of illness or disease (e.g. cancer) is very tenuous for most chemicals so that it is difficult to determine any measure of the health effects based on toxicological studies (Kraus et. al. 1993).

Yet there is great concern from the public regarding the impact that hazardous waste will have on their lives and this has affected the decision process regarding the cleanup of hazardous waste. The results of a national opinion poll in which experts and citizens ranked environmental health risks revealed that hazardous waste sites were at the top of the public's ranking of risks while they were categorized as medium to low by scientific experts (Sunstein 1996 p. 265).

Consider the challenge in providing insurance coverage for leaking USTs discussed in the introductory section. One would need to know the probability of a leak from a tank of a particular age and type as well as the expected costs of cleaning up the contaminated waste from leaks of different magnitudes and the cost of replacing the tank. These data could form the basis for a private insurance program. To estimate the premium one would have to inspect the tank to determine its current condition. Regular inspections of the tank over time would reduce the chances of future leaks and reduce the premiums accordingly. Finally replacing an old tank with a new one is a form of loss prevention that may also be cost effective (Freeman and Kunreuther, in press).

There are two complementary solutions to making the risk insurable, both of which require some type of government involvement. By having well-specified standards for specifying "how clean is clean" with respect to waste remediation, it should then be possible to bracket the cost associated with a leaking UST more precisely than one can today. To the extent that there was concern that these standards would change through new legislation, insurers could purchase some type of financial instruments to protect themselves against unexpected losses due to the resulting highly correlated risks. ${ }^{29} \mathrm{As}$ in the previous example, public provision of insurance and reinsurance should be avoided unless insurers could make a case that they might become insolvent without this form of protection.

Today state guarantee funds (SGFs) provide small and large businesses with relatively inexpensive coverage on both past liabilities and future leaks. Several of these SGFs are going bankrupt because the funds which they have collected are insufficient to pay for the losses incurred. Such government subsidized activities should be discontinued since they drive out private insurance. Rather than utilizing mechanisms, such as SGFs, it would be more desirable to provide low-interest loans or special grants to small business to enable them to clean up their old tanks, so they could then purchase private insurance on new ones (Boyd and Kunreuther 1997).

${ }^{29}$ There might be a moral hazard problem if the purchase of such protection impacted on the legislative process. 


\section{Conclusions and suggestions for future research}

This paper argues for a new approach for dealing with catastrophic accidents and disasters which takes advantage of recent developments in information technology and the emergence of new financial instruments to deal with non-diversifiable risks. These two major changes open up opportunities for residents and firms to undertake cost-effective loss prevention measures while at the same time providing a financial cushion to insurers concerned with the possibility of insolvency.

There are a set of open questions as to the types of incentives insurers can provide to individuals who invest in loss mitigation measures, and what types of financial instruments insurers should purchase to supplement or replace traditional reinsurance coverage. A strategy for undertaking research in this area would involve the analysis of the impact of disasters or accidents of different magnitudes on a set of structures, industrial plants or their equipment (e.g. USTs).

In order to determine expected losses and the maximum probable losses arising from worst case scenarios, it may be necessary to undertake long-term simulations. For example, one could examine the impacts of earthquakes of different magnitudes on the losses to a community or region over a 10,000 year period. In the process one could determine expected losses based on the probabilistic scenario of earthquakes as well as the maximum possible loss during this period based on a worst case scenario.

By constructing large, medium and small representative insurers with specific balance sheets, types of insurance portfolios, premium structures and a wide range of potential financial instruments, one could examine the impact of different disasters on the insurer's profitability, solvency and performance through a simulation. Such an analysis may also enable one to evaluate the risks associated with different types of financial instruments provided to different sized insurers with a given portfolio. These data could be used to determine the return an investor would require to provide capital for supporting each instrument. The selling prices of different types of financial instruments would reflect both the expected loss and variance in these loss estimates to capture risk aversion by investors. One could also examine the role of the public sector in regulating rates and providing protection against catastrophic losses. ${ }^{30}$

Two very important outcomes would emerge from such simulations. It should be possible to rank the importance of different financial instruments for different types of firms. Thus small firms may prefer finite risk products while larger ones may want to rely on excess loss reinsurance due to a more attractive price for a pre-specified amount of protection. These simulation results could be compared with analytic studies of the performance of these instruments. If there are major differences it would be important to understand why they exist. Secondly, investors could determine whether the market price which emerged from this simulation would be sufficiently attractive for them to provide investment capital to support certain instruments.

${ }^{30}$ An example of such an approach to a model city in California facing an earthquake risk can be found in Kleindorfer and Kunreuther (1996). 
This is a very exciting time for the insurance and reinsurance industry to explore new opportunities for dealing with catastrophic risks. If insurance can be used as a catalyst to bring other interested parties and new financial instruments to the table, it will have served an important purpose in helping both the industry and society deal with the critical issue of reducing losses and providing protection against natural, technological and environmental disasters.

\section{APPENDIX \\ MODELING THE DEMAND FOR PROTECTION AND SUPPLY OF COVERAGE AGAINST CATASTROPHIC RISKS}

\section{Demand for insurance}

We will first consider the case where the individual does not consider investing in loss mitigation measures. The standard model for analyzing this problem is expected utility analysis ${ }^{31}$ where the potentially insured party wants to find the optimal amount of insurance $\left(I^{*}\right)$ which maximizes his or her expected utility $[E(U)]$ given by:

$$
\max E(U)=\pi U(W-L+I-z I)+(1-\pi) U(W-z I)
$$

where $W=$ the individual's wealth, $L=$ loss from a disaster, $z=$ premium per dollar of insurance $I$ and $\pi=$ perceived probability of a disaster by the homeowner and $U$ is a von-Neumann Morgenstern utility function. The amount of insurance is restricted to $0 \leq I \leq L$. Note that $z$ is based on $\pi$ which may differ from the expert's probability $p$. Optimal coverage using (1) is determined by the following contingency price ratio $(R)$ :

$$
\mathrm{R}=\frac{(1-\pi) z}{\pi(1-z)}=\frac{U^{\prime}[W-L+(1-z) I]}{U^{\prime}(W-z I)}
$$

where $U^{\prime}=$ the marginal utility of a particular wealth level. When $R \leq 1$ then the individual will always buy full insurance $(I=L)$. When $R \geq U^{\prime}(W-L) / U^{\prime}(W)$ then an individual will want $I=0$.

${ }^{31}$ Machina (1995) has shown that when one utilizes generalized expected utility analysis, most of the results of expected utility theory with respect to the consumer demand for insurance coverage still hold. 


\section{Demand for protection}

Suppose that the homeowner is interested in determining how much money $(x)$ to invest in a protective measure without having purchased any insurance and assumes no public assistance should it suffer a disaster loss. If the structure is expected to last for $T$ years and the family's annual discount rate is $r$, then the optimal amount $\left(x^{*}\right)$ to invest in protective measures is determined by:

$$
\max E(U)=-x+\pi \sum_{t=0}^{T}(1-\pi)^{t-1} U[W-L(x)] /(1+r)^{t}
$$

From (2) one can see that as $\pi$ and/or $T$ increases then $x^{*}$ increases.

\section{A safety-first model of underwriter behavior}

Let $Y$ be a random variable representing the total loss from the insurer's current portfolio of risks and $A=$ the insurer's total assets. If the underwriter is considering whether to provide coverage for a risk in which the firm expects to sell $m$ policies, each of which can create a loss $L$, then a safety first model implies that the underwriter will recommend a premium $z^{*}$ so that

$$
\sum_{j=1}^{m}\left\{\text { Probability }\left[(Y+j L)>\left(A+m z^{*}\right)\right]\right\}<q^{*}
$$

where $q^{*}$ is a preassigned probability that reflects the threshold insolvency probability that the firm is willing to tolerate. As $m$ decreases and/or the correlation between losses decreases, the insurer will require a lower premium $z^{*}$ to satisfy (3).

\section{Impact of financial instruments on survival constraint}

Let $B$ be the amount of capital which an insurer receives should it negotiate some type of financial arrangement like a finite risk product or Act of God bond; Suppose $Z$ reflects the annual premium which the insurer pays to obtain these funds when a disaster occurs (e.g. the extra amount paid by the insurer in interest rate differential in return for $B$ dollars provided to the insurer following a catastrophic disaster). Then (3) becomes:

$$
\sum_{j=1}^{m}\{\text { Probability }[(Y+j L-B)>(A+m z-Z)]\}<q^{*}
$$

Note that as $B$ increases relative to $Z$ in (4), the insurer will feel less constrained regarding the number of policies $m$ it writes for the new type of risk. Furthermore for any given value of $m$, the premium $r$ will now be decreased. Viewed in this way the underwriter should then be able to specify the magnitude of the needed funds $(B)$ in relation to the cost $(Z)$ to provide coverage against a risk which has catastrophic potential. 


\section{REFERENCES}

ARROW, K. (1971) Essays in the Theory of Risk Bearing, Chicago: Markham.

BERGER, L. and KUNREUTHER, H. (1994) "Safety First and Ambiguity", Journal of Actuarial Practice 2, pp. 273-291.

BESTWEEK (1996) "Catastrophes: A Major Paradigm Shift for P/C Insurers", BestWeek: Property Casualty Supplement P/C pp. 1-18, (March 25).

BOYD, J. and KUNREUTHER, H. (1997) "Retroactive Liability or the Public Purse: Who should be

- Responsible for Historic Environmental Costs?", Journal of Regulatory Economics, 11, pp. 79-90.

CULP, C. (1996) "Relations Between Insurance and Derivatives: Applications from Catastrophic Loss Insurance", Paper Presented at "Rethinking Insurance Regulation" (Washington, D.C.: Competitive Enterprise Institute) (March 8).

CUMMINS, D. and GEMAN, H. (1995) "Pricing Catastrophe Insurance Futures and Call Spreads: An Arbitrage Approach", The Journal of Fixed Income, pp. 46-57 (March).

DIONNE, G. and EECKHOUDT, L. (1985) "Self-Insurance, Self Protection and Increased Risk Aversion", Economic Letters, 17, pp.39-42.

DIONNE, G. and HARRINGTON, S. (1992) "An Introduction to Insurance Economics" in Dionne, Georges and Harrington, Scott ed. (1992), Foundations of Insurance Economics, (Kluwer: Boston).

DIONNE, G. and HARRINGTON, S. ed. (1992) Foundations of Insurance Economics, (Kluwer: Boston).

DOHERTY, N. (1991) “The Design of Insurance Contracts when Liability Rules are Unstable”, Journal of Risk and Insurance, 63, pp. 227-246.

DOHERTY, N. and TINIC, S. M. (1982) "A Note on Reinsurance under Conditions of Capital Market Equilibrium", Journal of Finance, 36, pp. 949-953.

EHRLICH, I. and BECKER, G. (1972) "Market Insurance, Self-Insurance and Self Protection", Journal of Political Economy, 80, pp. 623-648.

EMERSON, B. and STEVENS, T. (1995) "Natural Disasters: A Budget Time Bomb”, Washington Post, (Oct. 31), p. A13.

ER, J. P. (1996) "A Third Party Approach to Environmental Regulation and Possible Roles for Insurance Companies", PhD Dissertation, University of Pennsylvania.

ER, J. P., KUNREUTHER, H. and ROSENTHAL, I. (1996) "Challenges in Utilizing Third Party Inspections for Preventing Major Chemical Accidents" (mimeo).

Federal Emergency Management Agency (1994) Assessment of the State-of-the Art Earthquake Loss Estimation, Washington, D.C.: National Instiution of Building Sciences.

FREEMAN, P. and KUNREUTHER, H. (in press) Managing Environmental Risk Through Insurance, (Boston: Kluwer and Washington, D.C.: American Enterprise Institute).

FROOT, K., SCHARFSTEIN, D and STEIN, J. (1994) “A Framework for Risk Management, Harvard Business Review, Nov.-Dec., pp. 91-102,

FROOT, K., MURPHY, B., STERN, A. and USHER, S. (1995) The Emerging Asset Class: Insurance Risk, New York: Guy Carpenter \& Co., July.

GILES, M. (1994) "A Survey of Insurance" The Economist, Dec. 3, pp. 3-22.

HARRINGTON, S., MANN, S. and NIEHAUS, G. (1995) "Insurer Capital Structure Decisions and the Viability of Insurance Derivatives", The Journal of Risk and Insurance, 3, pp.483-508. 
HIEBERT, L. D. (1989) “Optimal Loss-Reduction and Increases in Risk Aversion”, Journal of Risk and Insurance, 56, pp.300-305.

Insurance Information Institute (1995) "Insurance Issues Update" (New York).

Insurance Research Council and Insurance for Property Loss Reduction (1995) Coastal Exposure and Community Protection: Hurricane Andrew's Legacy, [Wheaton, I11 (IRC) and Boston (IIPLR)].

Insurance Services Office (1996) "Managing Catastrophic Risk", (New York, N.Y.: Insurance Services Office).

JAFFEE, D. and RUSSELL, T. (1996) "Catastrophe Insurance, Capital Markets, and Uninsurable Risks", Paper presented at the Wharton Financial Institutions Center Conference: Risk Management in Insurance Firms, May.

JOHNSON, E., HERSHEY, J., MESZAROS, J. and KUNREUTHER, H. (1993) "Framing, Probability Distortions, and Insurance Decisions", Journal of Risk and Uncertainty, 7, pp. 35-52.

KLEIN, R. (1995) “Insurance Regulation in Transition”, Journal of Risk and Insurance, 3, pp. 363-404.

KLEINDORFER, P. and KUNREUTHER, H. (1996) "Challenges Facing the Insurance Industry in Managing Catastrophic Risks", Paper prepared for the National Bureau of Economic Research Conference on "The Financing of Property/Casualty Risks", Palm Beach, Florida, November, 21-23.

KRAUS, N. MALMFORS, T. and SLOVIC, P. (1993) "Intuitive Toxicology: Expert and Lay Judgement of Chemical Risks", Risk Analysis, 12, pp. 215-232.

KUNREUTHER, H. et al. (1978) Disaster Insurance Protection: Public Policy Lessons, (New York: Wiley).

KUNREUTHER, H. (1989) "The Role of Actuaries and Underwriters in Insuring Ambiguous Risks", Risk Analysis, 9, pp. 319-28.

KUNREUTHER, H., MESZAROS, J. HOGARTH, R. and SPRANCA, M. (1995) "Ambiguity and Underwriter Decision Processes", Journal of Economic Behavior and Organization, 26, pp. 337-352.

KUNREUTHER, H. and KLEFFNER, A. E. (1992) "Should Earthquake Mitigation Measures Be Voluntary or Required?", Journal of Regulatory Economics, 4, pp. 321-335.

LEMAIRE, J. (1986) Théorie Mathématique des Assurances, Belgium: Presse Universitaire de Bruxelles

LEWIS, C. and MURDOCK, L. (1996) "The Role of Government Contracts in Discretionary Reinsurance Markets for Natural Disasters", The Journal of Risk and Insurance, 4, pp. 567-97.

LITZENBERGER, R. BEAGLEHOLE, D. and REYNOLDS, C. (1996) Assessing Catastrophe-Reinsurance-Linked Securities as a New Asset Class, (New York: Goldman Sachs, July).

LOWENSTEIN, G. (1987) "Anticipation and the Valuation of Delayed Consumption", Economic Journal, 97, pp. 666-84.

MACHINA, M. (1995) "Non-expected Utility and the Robutness of the Classical Insurance Paradigm", The Geneva Papers on Risk and Insurance Theory, 20, pp. 9-50.

MARSHALL (1976) "Moral Hazard”, The American Economic Review, 66, pp. 880-890.

MAYERS, D. and SMITH, C. (1982) "On Corporate Demand for Insurance", Journal of Business, 55, pp. 281-296.

MAYERS, D. and SMITH, C. (1990) "On Corporate Demand for Insurance: Evidence from the Reinsurance Market”, Journal of Business, 63, pp. 19-40. 
MITTLER, E., TAYLOR, C. and PETAK, W. (1995) "National Earthquake Probabilistic Hazard Mapping Program: Lessons for Knowledge Transfer". Report prepared for U.S. Geological Survey, (December 31).

MOONEY, S. (1995) "Presentation to Academic Task Force on Hurricane Insurance", (May 23) (mimeo).

OFFICE OF TECHNOLOGY ASSESSMENT (1995) Reducing Earthquake Losses, Washington, D.C.: USGPO.

PALM, R., HODGSON, M. BLANCHARD, R. D. and LYONS, D. (1990) Earthquake Insurance in California: Environmental Policy and Individual Decision Making, (Boulder: Westview Press).

PALM, R. (1995) Earthquake Insurance: A Longitudinal Study of California Homeowners, Boulder: Westview Press.

PAULY, M. (1974) "Overinsurance and Public Provision of Insurance: The Role of Moral Hazard and Adverse Selection" Quarterly Journal of Economics, 88, pp. 44-62.

PRIEST, G. (1987) “The Current Insurance Crisis and Modern Tort Law”, Yale Law Journal, 96, pp. $1521-1590$

ROTH, R., Jr. (in press) "Earthquake Insurance Protection in California", in Kunreuther, Howard (ed.), The Role of Insurance in Natural Disasters, Washington, D.C.: Joseph Henry Press.

ROY, A. D. (1952) "Safety-First and the Holding of Assets", Econometrica, 20, pp. 431-449.

RUSSELL, T. and JAFFEE, D. (1996) "Sharing the Risk: Northridge and the Financial Sector", Paper prepared for EERI/FEMA Conference "Analyzing Economic Impacts and Recovery from Urban Earthquakes", Pasadena, CA, October, pp. 10-11.

SCISM, L. (1996) "Florida Homeowners Find Insurance Pricey If They Find It At All", Wall Street Journal, July 12 , p. 1 .

SHAVELL, S. (1979) "On Moral Hazard and Insurance", Quarterly Journal of Economics, 93, pp. 541-562.

SHRIVASTAVA, P. (1987) Bhopal: Anatomy of a Crisis, Cambridge, MA: Ballinger.

Sigma (1995) Natural Catastrophes and Major Losses in 1995, (Zurich: The Swiss Re).

SPENCE, M. and ZECKHAUSER, R. (1971) "Insurance, Information and Individual Action" American Economic Review, 61, pp. 380-387.

STONE, J. (1973) "A Theory of Capacity and the Insurance of Catastrophic Risks: Part I and Part II, Journal of Risk and Insurance, Vol. 40, 1973, pp. 231-243 (Part I) and Vol. 40, pp. 339-55 (Part II).

SUNSTEIN, C. (1996) "Congress, Constitutional Moments and the Cost Benefit State", Stanford Law Review, 48, pp. 247-309.

VALERY, N. (1995) "Fear of Trembling", The Economist, (April 22), p. 11.

WALKER, G. (1996) "Earthquake Insurance Issues", Paper presented at the 1996 Annual Conference of New Zealand National Society for Earthquake Engineering (New Plymouth).

WEINSTEIN, N. ed. (1987) Taking Care: Understanding and Encouraging Self-Protective Behavior, Cambridge: Cambridge University Press.

ZECKHAUSER, R. (1995) "Insurance and Catastrophes", The Geneva Papers on Risk and Insurance Theory, 20, pp. 157-76. 